\title{
ON THE ROLE OF GLONASS FOR THE DEVELOPMENT OF THE RUSSIAN GEODETIC REFERENCE NETWORK
}

\author{
Kuzin Sergey ${ }^{\mathrm{b}}$, Mitrikas Vladimir ${ }^{\mathrm{a}}$, Revnivykh Sergey ${ }^{\mathrm{a}}$, Tatevyan Suriya ${ }^{\mathrm{b}}$ \\ ${ }^{\text {a }}$ Central Research Institute of the Federal Space Agency, 4, Pionerskaya \\ str.141070, Korolev (Moscow), RF. Sergey.revnivykh@mcc.rsa.ru \\ b Institute of Astronomy, Russian Academy of Sciences,48, Pyatnitskaya \\ str.119017,Moscow,RF statev@,inasan.ru
}

\begin{abstract}
The combined use of GPS and GLONASS satellite systems is a main technology for the development of the fundamental geodetic network in Russia and for crust movement studies along the North Eurasian tectonic plate. All permanent stations of the state fundamental geodetic network will be provided with the two frequency GPS and GLONASS receivers. A collocation of these stations with the existing Russian sites of the international GNSS (Global Navigation Satellite System) network is foreseen. The GLONASS state program foresees to come to 18 satellites in constellation in 2007-2008, and full operation capability (24 satellites) will be reached by 2009. The second generation of satellites: GLONASS-M have the L2 civil signal, extended lifetime and improved clock stability. GLONASS-K satellites are expected by 2009 with the L3 civil signal and Synthetic Aperture Radar function. A combination of GPS and GLONASS will benefit the scientific geodynamic research and practical users, especially in the urban, mountain and near polar areas. Results of the experimental GLONASS data analysis performed. Comparison of mean values of coordinates from only GLONASS solution, obtained at the Institute of Astronomy (Moscow) with the use of GIPSY-OASIS2 software, with the mean values from the GPS PPP solution for the IGS sites showed that differences are mainly within a few $\mathrm{cm}$, provided that incomplete configuration of GLONASS satellites have been observed.
\end{abstract}

Key words: fundamental geodetic network, GPS and GLONASS combined use, positioning

\section{NEW GEODETIC REFERENCE NETWORK IN RUSSIA}

An establishment the present-day heterogeneity of the Eurasia was one of the most significant achievements of regional geodynamics during last decade. Studies of the seismic belts of Eurasia and velocities of the crust movement, estimated with the use of GPS measurements at the sites of the international GNSS network, showed that only a northern part of the continent could be classified as an indivisible lithosphere plate (Gatinsky, et al., 2005) It could be named the North Eurasian Plate unlike the Eurasian Plate, which doesn't exist now as an indivisible tectonic element. 
With the purpose of improving the national geodetic reference frame an establishment of the new Fundamental Astro-Geodetic network (FAGN), based mainly on the combined use of GPS and GLONASS measurements, is now carried out in Russia, under the management of the Federal Department of Geodesy and Cartography in collaboration with the Academy of Sciences. (Demianov and Tatevian, 2000; Demianov et al.2005). A combination of GPS and GLONASS will strengthen the benefits both for scientific research and for practical users, especially in the urban, mountain and near polar areas. The FAGN will consist of about 40 fiducial sites in 700 $800 \mathrm{~km}$ distance each other and equipped with dual GPS and GLONASS receivers. (Kuzin et al. 2007).

\section{GLONASS NATIONAL PROGRAM}

GLONASS is a dual use Russian satellite navigation system for positioning, navigation and time service. Compatibility and interoperability of GLONASS with GPS and future Galileo system is an important issue of the National program. The State concept of the Russian United Positioning, Time and Navigation Service was approved in October 2004 by the Federal Government and then corrected by the President in January of 2006. In accordance with the Presidential Directive a full operation capability of the GLONASS system (24 satellites) should be achieved by 2009 with a performance comparable with GPS and future Galileo. (Plug, et al. 2004).

The complete constellation of the GLONASS will consist of 24 satellites at three orbital planes, 8 satellites in each. Inclination of the orbit is $64.8^{0}$, height $19100 \mathrm{~km}$ and revolution time $11 \mathrm{~h} 15 \mathrm{~min}$.

To improve the accuracy of the GLONASS system the new type of spacecrafts "GLONASS M" has been launched since 2005. These satellites have 7 years lifetime, power supply $1450 \mathrm{~W}$, clock stability (24 hours) of 1.E-13. Second civil signal at L2 frequency band is added and the attitude control accuracy has been improved to 0.5 degree. An improved solar panel pointing (2 degrees) will provide the better dynamical model of satellite orbits and less level of unpredicted accelerations. The third civil signal at L3 frequency will be included in the new generation of spacecrafts "GLONASS K", as well as better solar panel pointing of 1degree and SAR function. These satellites are planned for 2007-2008.

\section{GLONASS DATA ANALYSIS}

Information and Analytical navigation Center (IAC), responsible for monitoring of GLONASS performance, was founded in 1995 as a part of Russian Mission Control Center (MCC). Currently IAC is the official analysis center of the Russian Space Agency (RosCosmos). For this purpose two main nearly independent directions of data processing are implemented: precise orbit and clock determination and integrity monitoring. The only crossing of this analysis is the input data, which are collected of all available open sources. Real-time monitoring is based on the data of several proper receivers. Part of the results derived from civil L1-signal analysis is available via INTERNET (www.glonass-ianc.rsa.ru). In the post-processing these data are mixed with the data of several Russian and IGS stations in order to estimate system performance in terms of accuracy, availability and integrity. This analysis is primarily oriented on the resulting system performance in particular at the user level.

The other direction of data processing is precise orbit and clock determination, which is performed in the routine mode since 2004. IAC is associated analysis center of the International GPS (GNSS) Service (IGS) regularly providing GLONASS a posteriori orbit and clock data. 
Like most of IGS analysis centers IAC utilize three levels of data processing: final, rapid and ultra-rapid where similar but partially different sets of task are solved. The models used generally follow IGS recommendations. The most accurate final data are used to assess the accuracy of orbit and clock data as well as additional characteristics like stability of the onboard frequency standards, the behavior of system time scale, reproduction of reference system, etc. Hence this analysis is mostly oriented on the assessment of control segment.

In order to validate the quality of proper solutions the precise point positioning -PPP (Zumberge et al., 1997) for extended set of receivers is performed every processing cycle. In fact pure GLONASS PPP solution can hardly be performed due to the limitations of the orbital constellation. Usually there is no difference if GPS or both GPS and GLONASS data are used. The noise of 5-min station coordinates is about $2-3 \mathrm{~cm}$.

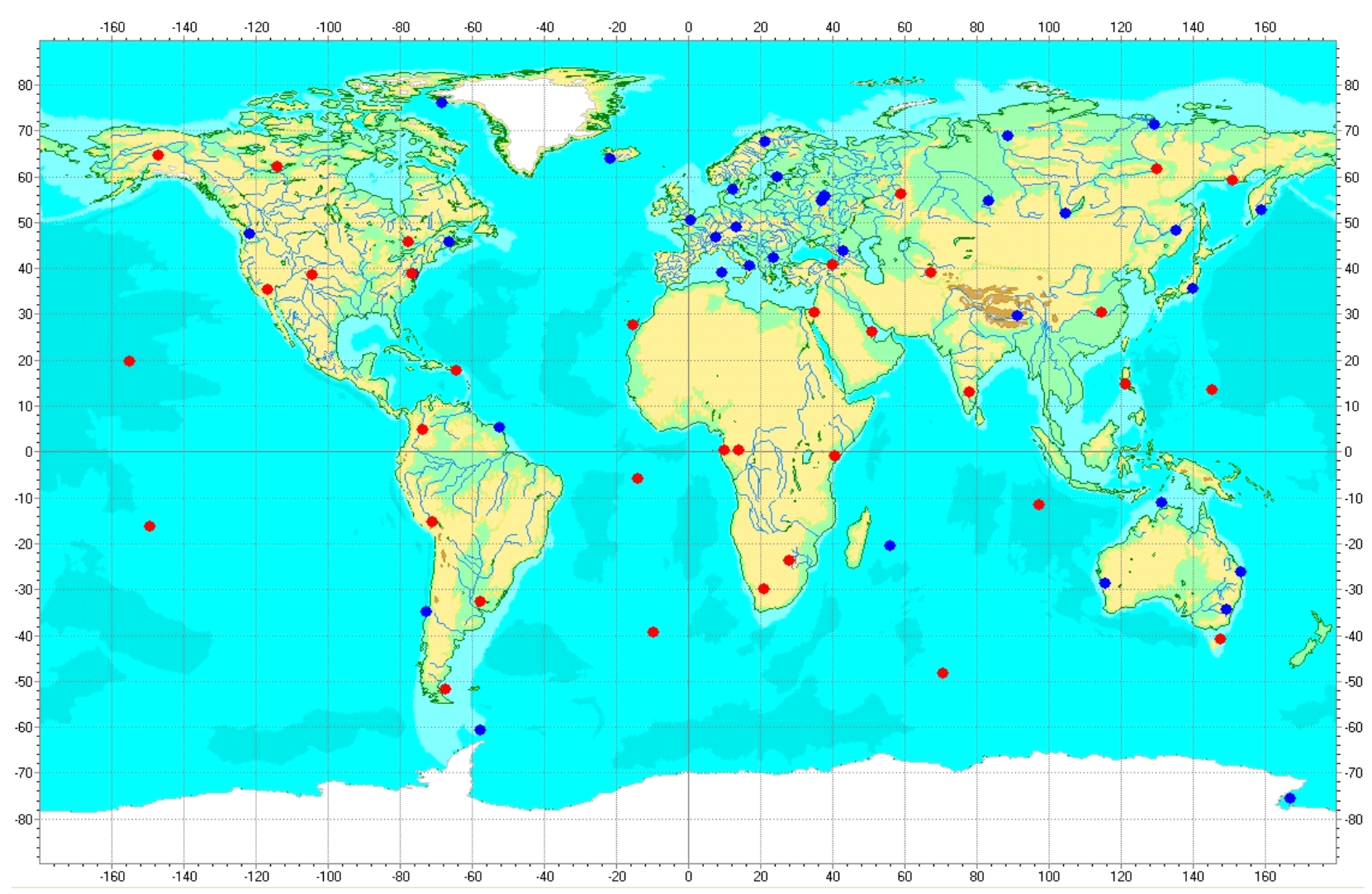

Fig.1. GPS and GLONASS sites used for estimation of the accuracy of the GLONASS orbital and clock data at the IAC

Typically about 30-35 combined GLONASS/GPS and 30-35 GPS only receivers are involved to the final solutions (fig.1). Final clock values are aligned to GPS and GLONASS time respectively.

The accuracy of the solutions is routinely compared with final IGS values available with the delay of up to few weeks (for GLONASS data). Internal analysis results $9 \mathrm{~cm}$ orbit RMS and 0.3 ns clock RMS wrt IGS final values, and $10 \mathrm{~cm}$ RMS for GLONASS orbits (IGS GLONASS clocks are not available). IGS analysis shows better values for GLONASS orbits. Currently only two analysis centers provide GLONASS a posteriori clocks: IAC and ESOC (European Space Agency Operational Center). Typical difference after the removal of the time scale bias is around 
of $1.5 \mathrm{~ns}$. Since 2007, June the systematic difference between IAC and IGS clocks rarely exceed $0.5 \mathrm{~ns}$ in the worst case.

Unlike the GPS, all GLONASS data are biased mostly due to non-linear characteristics of high-frequency filters. There is a strong correlation between biases and frequency channels but in precise applications biases of opposite satellites are not absolutely compatible perhaps due to different satellite specific reasons. The other problem is valuable difference between different types of the combined receivers like Ashtech-Z18, Javad-Topcon, Trimble and Leica. Since the biases are grouped by the receiver type for a certain satellite, tracked by mostly Javad receivers, all Ashtech receivers may look as outliers and vice versa.

Manufacturing of linear high-frequency filters probably will become possible in 2-3 years.

IAC analysis shows that the main reasons of the too high ephemeris errors are unstable biases in the control segment and in stability of the onboard frequency standards. According to the federal program coordinated by RosCosmos the deep upgrade of the GLONASS control segment should be implemented in the next three years making the emphasis on the transmission from two-way to one-way tracking. Extreme stability of GPS-IIR standards can hardly be achieved in near future. But the estimation of the GLONASS-M standards shows optimistic trend. It should be noted that all GLONASS-M satellite, except 711 (R06), transmit L2 civil signal. The change to the enhanced version of PZ-90/2 reference frame, which is close to ITRF has been made in September, 2007. If GLONASS-M spacecrafts lifetime meets these specification, there is no doubts in the realization of GLONASS and GPS compatibility and interoperability in terms of accuracy.

\section{PRECISE POSITIONING WITH GLONASS}

As it was mentioned above at present the GLONASS system has an incomplete constellation and no more than 10 satellites are in operational mode simultaneously. In general the GLONASS performance is very satisfactory in geodetic applications such as single receiver positioning, being free of the selective availability degradation. Final results of the International campaigns IGEX and IGLOS confirmed that GLONASS is a good alternative and a complement to the GPS system. (Willis, et al.1999, Weber, et al. 2005) To investigate the possibility of precise positioning with the use of incomplete GLONASS constellation an experimental analysis of the weekly data (25. 11. 2005 to 03. 12.2005), obtained at the sites of the international network, has been performed. At present within the International GNSS Service there are 52 stations with the GPS and GLONASS dual receivers. 29 sites at a long distance each other and located at different continents and islands have been chosen for the analysis.. Calculations have been performed with the help of GIPSY-OASIS II software package (Webb and Zumberge,1995). The method of twostep approach was applied for evaluation of station coordinates, as it was described by Kuang et al., 2001. At first, we used the PPP technique for estimation of station-specific parameters: precise position, clock and troposphere parameters for each site (Zumberge et al., 1997). At this step transmitter clock parameters and GPS orbit were fixed to the precise ephemeris and clock corrections, produced at the JPL with the use of IGS/FLINN (Fiducial Laboratorial International Natural-Science Network) data (Jefferson et al., 1998). The coordinates of all 29 sites have been estimated with the mean square residuals (r) of about $2-4 \mathrm{~mm}$. This point positioning solution ties the GLONASS tracking network to the reference system ITRF2000 (Altamimi et al., 2002), in which the GPS precise ephemeris were defined. At the second step the coordinates of 16 stations of the test network are considered fixed to their values, obtained from the PPP GPS 
solution, and only CLONASS data are processed for the rest 13 sites of the test network. At that time the GLONASS constellation had only12 satellites (No. 1, 2, 3, 4, 5, 6,17, 18, 21, 22, 23, 24). Three of them $(1,2,6)$ had a small number of measurements, compared with others, and have been removed from calculations. The precise orbits of the GLONASS satellites, transmitter clock biases, troposphere delays and station positions for all sites are estimated simultaneously. To strengthen an adjustment of the GLONASS data three days orbital arcs were used for every daily solution. The GPS Block II solar radiation pressure model was used for GLONASS satellites, as the attitude control scheme of GLONASS satellites is the same as for GPS satellites. In this solution residuals of the estimated horizontal components of the coordinates are mainly within the 1-2 cm. Mean values of coordinates (three components E-east, N-north, U-up) of 13 stations from only GLONASS solution have been compared with the mean coordinates from GPS PPP solution. The differences and their residuals are presented in Table 1. The differences are mainly within a few cm, except of DWH1 (USA) and YARR (Australia) sites. This could be explained by a small amount of measurement data at these sites. Besides it should be noted, that dependence of the phase centers variations of the GLONASS receiving antennas on the satellite azimuth and elevation, as well as, phase centers positions relatively to the antenna reference points, was not taken into account. These facts may be the reason of greater differences in height components of coordinates between the GPS and only GLONASS solutions. 
Table 1. Differences and their residuals between mean values of station coordinates, estimated by GLONASS and GPS solutions for the week 26 November 2005-3, December 2005. All units are in mm for three components (E, N, U) of the position vectors. The sites with fixed coordinates, obtained from only GPS solution, are shown in bold type.

\begin{tabular}{|c|c|c|c|}
\hline \multirow[b]{2}{*}{ Station } & \multicolumn{3}{|c|}{ "GLONASS - GPS } \\
\hline & East $(\mathrm{mm})$ & North (mm) & $\mathrm{Up}(\mathrm{mm})$ \\
\hline BOGI & $0.5 \pm 4.2$ & $0.8 \pm 4.7$ & $-98.4 \pm 5.0$ \\
\hline CAGZ & $-13.9 \pm 2.7$ & $-3.1 \pm 3.0$ & $-63.7 \pm 3.1$ \\
\hline DLFT & $-3.6 \pm 1.9$ & $5.9 \pm 2.4$ & $-78.2 \pm 2.5$ \\
\hline DREJ & $-1.7 \pm 2.0$ & $3.0 \pm 2.3$ & $-90.3 \pm 2.3$ \\
\hline DWH1 & $36.8 \pm 11.0$ & $17.7 \pm 11.6$ & $-112.0 \pm 11.7$ \\
\hline FFMJ & $-5.9 \pm 1.9$ & $0.6 \pm 2.3$ & $-92.9 \pm 2.4$ \\
\hline GODZ & $8.1 \pm 9.0$ & $-24.3 \pm 8.4$ & $-69.3 \pm 8.6$ \\
\hline GOPE & $-3.3 \pm 2.0$ & $0.9 \pm 2.4$ & $-49.0 \pm 2.4$ \\
\hline HERT & $-15.6 \pm 2.0$ & $5.6 \pm 2.5$ & $-89.9 \pm 2.5$ \\
\hline IRKJ(fixed) & $-0.7 \pm 0.0$ & $-0.9 \pm 0.0$ & $11.0 \pm 0.0$ \\
\hline $\mathrm{JOZ2}$ & $6.7 \pm 1.8$ & $0.6 \pm 2.2$ & $-98.1 \pm 2.2$ \\
\hline KHAJ(fixed) & $0.1 \pm 0.0$ & $-1.9 \pm 0.0$ & $2.4 \pm 0.0$ \\
\hline KIRO & $2.4 \pm 1.7$ & $-0.3 \pm 2.1$ & $-4.3 \pm 2.9$ \\
\hline KOU1(fixed) & $3.4 \pm 0.0$ & $-3.9 \pm 0.0$ & $7.1 \pm 0.0$ \\
\hline LEIJ(fixed) & $-0.9 \pm 0.0$ & $0.5 \pm 0.0$ & $0.6 \pm 0.0$ \\
\hline MAR6 & $-17.7 \pm 1.6$ & $-4.7 \pm 2.0$ & $-6.6 \pm 2.3$ \\
\hline MAT1 & $-6.1 \pm 2.5$ & $2.8 \pm 2.8$ & $-94.8 \pm 2.8$ \\
\hline MDVJ(fixed) & $0.3 \pm 0.0$ & $-1.2 \pm 0.0$ & $5.8 \pm 0.0$ \\
\hline METZ(fixed) & $-0.2 \pm 0.0$ & $-2.9 \pm 0.0$ & $6.7 \pm 0.0$ \\
\hline MTKA(fixed) & $-0.1 \pm 0.0$ & $-0.4 \pm 0.0$ & $0.8 \pm 0.0$ \\
\hline NOVJ & $-1.4 \pm 2.3$ & $-3.5 \pm 2.8$ & $-30.9 \pm 3.0$ \\
\hline ONSA(fixed) & $-0.5 \pm 0.0$ & $-0.3 \pm 0.0$ & $4.0 \pm 0.0$ \\
\hline REUN(fixed) & $0.0 \pm 0.0$ & $-1.0 \pm 0.0$ & $-6.2 \pm 0.0$ \\
\hline REYZ & $-7.5 \pm 2.5$ & $12.3 \pm 3.2$ & $-63.1 \pm 3.8$ \\
\hline SASS & $3.9 \pm 1.7$ & $1.6 \pm 2.1$ & $-98.6 \pm 2.2$ \\
\hline SOFI(fixed) & $-6.2 \pm 0.0$ & $-0.2 \pm 0.0$ & $-8.1 \pm 0.0$ \\
\hline SPTO & $3.2 \pm 1.6$ & $3.3 \pm 2.1$ & $-11.0 \pm 2.3$ \\
\hline STR2(fixed) & $-8.1 \pm 0.0$ & $0.4 \pm 0.0$ & $-10.0 \pm 0.0$ \\
\hline SUNM(fixed) & $0.4 \pm 0.0$ & $0.9 \pm 0.0$ & $9.8 \pm 0.0$ \\
\hline THU2(fixed) & $-2.0 \pm 0.0$ & $0.8 \pm 0.0$ & $-4.4 \pm 0.0$ \\
\hline TITZ & $-12.8 \pm 2.0$ & $8.5 \pm 2.5$ & $-91.3 \pm 2.5$ \\
\hline UNFE & $-2.5 \pm 2.1$ & $2.1 \pm 2.5$ & $-109.7 \pm 2.5$ \\
\hline VENE & $-2.5 \pm 2.2$ & $-1.6 \pm 2.6$ & $-86.8 \pm 2.6$ \\
\hline VIS0 & $3.0 \pm 1.7$ & $1.6 \pm 2.0$ & $-15.7 \pm 2.3$ \\
\hline WARN & $-0.8 \pm 1.7$ & $4.8 \pm 2.2$ & $-106.4 \pm 2.3$ \\
\hline WTZR & $3.0 \pm 2.0$ & $3.3 \pm 2.4$ & $-29.0 \pm 2.4$ \\
\hline WTZZ & $-3.4 \pm 1.9$ & $3.3 \pm 2.3$ & $-107.4 \pm 2.3$ \\
\hline YARR & $6.7 \pm 11.8$ & $-100.3 \pm 9.4$ & $-143.4 \pm 11.1$ \\
\hline ZIMJ (fixed) & $-10.2 \pm 0.0$ & $0.2 \pm 0.0$ & $0.0 \pm 0.0$ \\
\hline
\end{tabular}




\section{CONCLUSION}

According to the State Program of the GLONASS development a full constellation of 24 satellites will be deployed by 2009 year with performance comparable with GPS and Galileo, GLONASS is a main technology for establishment of the new Fundamental Geodetic Network in Russia. More than 20 permanent sites of this network will be provided with the dual GPS and GLONASS receivers in the next two years and will be connected with the international GNSS service. As it was described by Zarraoa et al. 1998, from the geodetic point of view, the advantages of combining both systems are numerous. With more observations and a better geometry an estimation of troposphere delay may be significantly improved. Our preliminary analysis confirms, that a combined use of GPS and GLONASS has to benefit users, especially in the urban, mountain and near polar areas.

\section{Acknowledgements}

The researches presented in this paper were partly supported by the Russian Basic Sciences Foundation ( RFFI 07-05-00409).

\section{REFERENCES}

Altamimi,Z., Sillard, P., Boucher, C. 2002. ITRF2000, A new release of the International Terrestrial Reference Frame for Earth science application, J. Geophys. Res. 107(B10), 2214,.

Demianov G.V. and. Tatevian S.K, 2000. Integrated Geodynamical Network in Russia.

(Scientific objectives and Realization). Phys.Chem.Earth (A), 25, №12, 819-822.

Demianov G.V., Kuzin S.P., Tatevian S.K., 2005.On the unification of the European and Asian vertical datum. Proceedings of the APSG Symposium "Geodynamics and Natural Hazards". 15-17 June 2005, Hong-Kong, 227-233.

Gatinsky Yu.G., Rundquist D.V., Tyupkin Yu.S., 2005. Block structures and kinematics of Eastern and Central Asia from GPS data. Geotectonics, 39(5), 333-348.

Jefferson,D.C., Bar-Sever Y.E., Heflin M.B., et al. 1999. JPL IGS Analysis Center Report, International GPS Service for Geodynamics 1998 Technical reports, JPL, Pasadena, 89-97.

Kuang, D., Bar-Server Y.E., Bertiger W., et al. 2001. GPS-assisted GLONASS orbit determination, Journal of Geodesy, 75, № 11,. 569-574.

Kuzin, S., Revnivykh,S., Tatevian, S. 2007 :Glonass as a key element of the Russian positioning service. Advances in Space Research. 39(10) 1531-1538.

Plag H.-P., Johansson J.M. Bergstrand S. 2004 Geodetic Galileo: A test case for high accuracy applications of Galileo in the frames of the Galileo System test bed. Geoph. Res. Abstracts, 6, 06253..

Zarraoa N., Mai W., Sardon E. et al. 1998. Preliminary evaluation of the Russian GLONASS system as a potential geodetic tool, J.Geod., 72(6), 356-363. 
Webb, F., Zumberge, J. (eds), 1995 An introduction to GIPSY-OASIS II, Report JPLM D-11088, Jet Propulsion Laboratory, Pasadena.

Zumberge, J.F., Heflin M.B., Jefferson, D.C., et al. 1997 Precise point positioning for the efficient and robust analysis of GPS data from large networks, J.Geophys.Res., 102(B3), 5005-5016.

Received: 2007-09-11,

Reviewed: 2007-12-12, by Z. Rzepecka,

Accepted: 2008-12-27. 